\title{
REDUÇÃO DE CUSTOS EM TRANSPORTES RODOVIÁRIOS: O ESTUDO DE CASO DE UMA DISTRIBUIDORA MULTINACIONAL DE COMBUSTÍVEIS LÍQUIDOS
}

\author{
REDUCTION OF COSTS IN ROAD TRANSPORT: THE CASE OF A LIQUID FUELS MULTINATIONAL \\ DISTRIBUTOR
}

\section{Eduardo Picanço Cruz, D.Sc.}

Thyago Trigueiro Oliveira

\begin{abstract}
RESUMO
Os custos com transportes rodoviários hoje no Brasil no setor de distribuição de combustíveis líquidos são cada vez maiores e a redução destes é de extrema importância para as empresas. A valorização do transporte rodoviário fez com que o país tivesse uma hipertrofia neste setor e que a maior parte do escoamento das produções fosse feito pelo modal rodoviário. A redução de custos na cadeia de suprimentos encontra farto campo para atuação no transporte. Ao estudar o sistema de distribuição de uma empresa distribuidora de combustíveis líquidos, busca-se mostrar como um sistema de entregas pode ser eficiente, com baixo custo e com nível de serviço ótimo para os clientes trazendo economias de escala para as empresas. As referencias as quais este trabalho baseia-se estão apoiadas em conceitos como as parcerias em logística, que tem papel preponderante em um trabalho de otimização de transporte rodoviário, e a otimização de frota, que é fundamental para que haja redução dos custos fixos e menores despesas como conseqüência, trazendo com isso, agregação de valor a cadeia de suprimentos como um todo e grandes economias para a organização.
\end{abstract}

PALAVRAS-CHAVE: Logística. Transporte. Redução de custos.

\begin{abstract}
The costs of road transportation in Brazil today in the sector of distribution of liquid fuels are increasing and reduction of these is extremely important for companies. The recovery of road transportation has meant that the country had a hypertrophy in this sector and that most of the flow of productions was done by modal road. The reduction of costs from the supply chain do a great performance in the field of transportation. By studying the distribution system of a company distributor of liquid fuels, seeks to show how a system of deliveries can be efficient, with low cost and with great level of service to customers bringing economies of scale for companies. The references which this work is based are relying on concepts such as partnerships in logistics, which has leading role in a work of optimizing road transportation, and optimize fleet, which is vital to achieve reduction of fixed costs and lower expenditure as result, bringing with it, aggregation of value to supply chain as a whole, and big savings for the organization.
\end{abstract}

KEY-WORDS: Logistics. Transportation. Cost savings. 


\section{INTRODUÇÃO}

A Administração de Transportes é, sem dúvida, um dos maiores desafios das empresas atualmente. Com o fenômeno da integração logística e a crescente demanda por produtos e serviços em tempo cada vez menor, nos últimos 20 anos, as empresas passaram a dar uma importância muito maior ao seu sistema logístico, para que os desperdícios de recursos e tempo fossem evitados.

Segundo avaliação da doutrina, os custos com transporte chegam a 60\% dos custos logísticos. A redução de custos nessa área é muito importante, pois corresponde em média $20 \%$ do custo total das empresas, cada vez mais as empresas estão de olho nessa fatia do mercado, pois no Brasil chama a atenção por faturar mais de $\mathrm{R} \$ 40$ bilhões e movimentar $2 / 3$ do total de carga do país.

No Brasil, o transporte rodoviário representa o principal meio de movimentação de cargas. Este tipo de transportes é o transporte feito por estradas, rodovias, ruas e outras vias pavimentadas ou não com a intenção movimentar materiais, pessoas ou animais de um determinado ponto a outro. Representa a maior parte do transporte terrestre. 0 transporte rodoviario tem um custo que representa cerca de 12,75\% (FIGUEIRED0, FLEURY E WANKE, 2006) do PIB nacional.

Este é o principal sistema de transporte no Brasil. Por ele passam $56 \%$ das cargas movimentadas no País, contra $21 \%$ por ferrovia e $18 \%$ por hidrovia. A predominância deste tipo de transporte deve-se ao modelo de desenvolvimento implantado desde o período do governo JK, época do "governar é abrir estradas".

Assim, as empresas brasileiras sempre tiveram poucas alternativas para escoar suas produções, além disso, o sistema de entregas para o cliente em sua porta, sempre foi um diferencial para qualquer empresa, então, somando-se isso, a situação do modal rodoviário no Brasil é de uma hipertrofia, onde utilizam-se caminhões para transferência de produções e entregas aos clientes.

Olhando este panorama, neste trabalho será estudado o caso de uma grande empresa multinacional de distribuição de combustíveis líquidos, já introduzida no Brasil há decadas. Será mostrado como esta empresa precisou fazer um trabalho muito forte para reduzir custos em transportes, de forma a otimizar a aplicação do capital empregado para que o retorno financeiro fosse melhorado e empresa conseguisse implementar seus novos objetivos para a logística da empresa.

Visa-se com isso, mostrar e inspirar empresas de outros ramos a adotarem métodos para otimização do transporte rodoviário.

\section{LOGÍSTICA E GERENCIAMENTO DA CADEIA DE SUPRIMENTOS}

Muito discute-se hoje sobre Logística, Gerenciamento da Cadeia de Suprimentos, Gestão da Distribuição Física, Estoques e Gestão estratégica do transporte. As empresas buscam, a cada dia, mais formas de fazer com que seus produtos estejam no lugar certo e na hora em que consumidor precise.

Antes de apresentar as bases de pesquisa que fundamentam este trabalho, é necessário apresentar o conceito de gerenciamento da cadeia de suprimentos e logística. Muita confusão se faz entre estes dois termos, com um confundindo-se com o outro. Porém, é necessário 
mostrar a diferença entre os dois termos, baseados nas principais obras dos autores pesquisados para este trabalho.

Para Ballou (1980) a Logistica tem como função estudar formas de se obter melhor serviço e rentabilidade nos serviços de distribuição aos clientes e fornecedores com planejamento, organização e controle do fluxo de produtos.

Já para Dias (1993), a logística consiste em apenas dois subsistemas, um sendo a administração de materiais e outro a distribuição física.

Para Bowersox (2001) a logística é a integração de informações, transporte, estoque, armazenamento, manuseio de matérias-primas e embalagem, cuja responsabilidade operacional está diretamente ligada com a disponibilidade de matérias-primas, produtos semiacabados e estoques de produtos acabados, no local onde são requisitados, ao menor custo possível.

Segundo Figueiredo, Fleury e Wanke (2003), a melhor definição seria a do Council of Logistics Management (CLM), onde a logística seria uma parte componente daquilo que se entende por gerenciamento da cadeia de suprimentos. Citando sua obra: "logística é a parte do gerenciamento da cadeia de suprimento responsável pelo planejamento, implementação e controle, de modo eficiente e eficaz, do fluxo e armazenagem de produtos (bens e serviços) e informações relacionadas, do ponto de origem até o ponto de consumo, com vistas ao atendimento das necessidades dos clientes."

Esta definição converge com a de Ballou e parece ser a mais adequada. Neste estudo esta será a definição base para Logística.

Em relação a cadeia de suprimentos, esta é vista como algo mais complexo, onde a logística está inserida, porém não é apenas a extensão deste, onde se colocam os consumidores e fornecedores.

Para Slack (2002) a gestão da cadeia de suprimentos nada mais é que uma complexa gestão da interconexão das empresas que se relacionam entre ligações anteriores e posteriores aos principais processos da organização que produzem valor na forma de bens e serviços.

De acordo com Figueiredo, Fleury e Wanke (2003), a cadeia de suprimentos é uma integração dos principais processos do negócio a partir do consumidor final até o fornecedor inicial. Do mesmo modo, vê Bertaglia (2006), onde a cadeia de suprimentos está vinculada a variáveis internas e externas que afetam a organização e aos diferentes modelos de negócio nos segmentos industriais e empresas de serviço.

A partir destas definições é possível clarificar as idéias e partir ao objetivo deste estudo, em demonstrar a importância da redução de custos dentro de um ponto específico dentro do gerenciamento da cadeia de suprimentos e da logística, que a gestão de transporte rodoviário.

\section{A REDUCAO DE CUSTOS EM TRANSPORTES RODOVIÁRIOS}

A redução de custos em transportes rodoviários faz parte da redução de custos na cadeia de suprimentos. Formas de redução de custos de transporte rodoviário são mostradas por alguns autores. Várias práticas de gestão são adotadas, bem como, várias formas de operação, para que se obtenha redução de custos significativas.

Um ponto bastante discutido é a adoção de frota própria ou não. Este assunto, impacta 
diretamente em qualquer trabalho de redução de custos em transportes rodoviários e muitas empresas passam por momentos de escolha entre terceirizar ou ter uma frota própria. Neste estudo, a empresa estudada, optou por ter frota terceirizada, onde viu maiores oportunidades de economia.

Segundo Ballou (1980), organizações que buscam melhores desempenhos operacionais em cargas de grandes volumes, podem preferencialmente escolher transporte próprio, mesmo sacrificando um pouco a flexibilidade financeira. Em casos especiais onde as organizações precisem de, entrega rápida com confiabilidade muito elevada ou transporte de equipamentos especiais e um serviço disponível assim que necessário, devem ter uma frota própria para transporte.

Para Bertaglia (2006), a decisão de operar ou não com frota própria, tem que levar em conta vários fatores, como nível de serviço ao cliente, flexibilidade, controle, habilidades administrativas e retorno do investimento. Empresas possuidoras de veículos próprios, segundo ele, precisam seguir práticas importantes para manterem-se competitivas no mercado.

Pode-se afirmar que a terceirização do transporte rodoviário é quase unânime, salvo em casos específicos, como a melhor forma de reduzir custos, simplificar o processo logístico e manter um bom nível de serviço aos clientes. Assim, as empresas buscam cada dia mais, formas de maximizar suas margens reduzindo custos.

A redução de custos em transportes rodoviários, através de uma metodologia adequada para cálculo de custeio do frete, pode contribuir em muito para a formação de preços justos tanto para a empresa (ou apernas para ela, em caso de frota própria) quanto para o transportador, na opinião de Lima (2003).

Segundo este autor, no Brasil, o alto grau de pulverização do setor traz conflitos entre empresas, transportadores e motoristas autônomos, em relação ao valor do frete.

Assim, um trabalho bem realizado trabalhando-se com custos fixos e variáveis pode ajudar e muito uma organização a encontrar um frete justo, que remunere o transportador adequadamente e permita ao mesmo tempo redução de custos ou permita a empresa obter maior produtividade com redução de custos, em caso de frota própria.

Lima (2003) em seu estudo, ve como principais custos dentro do transporte rodoviário: pneus, combustíveis, IPVA (seguro obrigatório), salário do motorista, lubrificantes, manutenção, pedágio e custos administrativos. Acrescenta-se ainda como custo, a depreciação e a taxa de oportunidade, que mesmo não sendo desenbolsados, são vistos como reservas de capital que devem ser feitas para substituição da frota.

\section{PARCERIAS LOGÍSTICAS, GESTÃO DA CAPACIDADE E NÍVEL DE SERVIÇO AO CLIENTE}

Quando se fala em gerenciamento da cadeia de suprimentos e transportes rodoviários não se pode esquecer de três itens fundamentais: a gestão dos operadores logísticos, a gestão da capacidade e a gestão do nível de serviço aos clientes.

Hoje em dia, as organizações estão optando por atuar com poucos operadores, de modo a criar relacionamentos mais duradouros com estes, as chamadas parceiras logísticas.

Bowersox (1990, apud FLEURY, 2000), dizia que o relacionamento tradicional entre as 
organizações e seus transportadores, era algo baseado na desconfiança e no senso de adversidade, fazendo com que práticas vitais para o bom e perfeito funcionamento da cadeia logística, como programações de entrega, carregamento e descarregamento, simplesmente ficassem mínimas ou inviáveis.

A implementação de uma cultura que viabilizasse a parceria entre empresa e transportadores era fundamental para que fossem obtidas vantagens reais num sistema logístico. Culturalmente, principalmente no Brasil, é algo complicado e que requer um grande esforço de ambas as partes, além de comprometimento dos atores envolvidos no processo. La Londe (1989 apud FIGUEIREDO, FLEURY E WANKE, 2003), propôs que fosse criada essa cultura, onde as partes pudessem enxergar vantagens e obter ganhos nesta nova relação.

Assim, a limitação do número de transportadores, bem como a garantia de volume de carga, maior previsibilidade da capacidade, troca de informações e principalmente, comprometimento dos atores envolvidos, fariam segundo La Londe (1989 apud FIGUEIREDO, FLEURY E WANKE, 2003), com que fosse construída uma relação de parceira, onde ambas as partes, contratante e contratado, sairiam ganhando.

A parceira logística, faria com que os transportadores pudessem gerir melhor a capacidade da frota. Uma frota enxuta, porém otimizada é uma frota que atende a demanda exigida. Há duas formas estretégia de gestão da capacidade, segundo Figueiredo, Fleury e Wanke (2003):

- a capacidade "flutuante", onde os recursos acompanham a demanda exigida

- a capacidade "fixa", onde os recursos são suficientes para atender a determinado percentual da demanda máxima

A primeira estratégia consiste em, de acordo com a variação de demanda, fazer com que os recursos também sejam variáveis, de modo a atender todos os pedidos dentro do prazo estipulado. A utilização desta estratégia é recomendada para processos intensivos em mãode-obra abundante com pouca especialização e onde há investimentos mínimos em recursos físicos.

A segunda estratégia consiste em fixação de um nível de serviço, que é um percentual da demanda máxima. Essa estratégia deve levar em consideração o tipo de serviço e se os clientes estão dispostos a pagar ou esperar pela disponibilidade de produtos. Nesse tipo de estratégia, uma política de entregas deve ser feita e seguida, para que não haja ineficiências nos processos.

Uma adequada gestão de capacidade, tem reflexos no que é chamado de nível de serviço ao cliente, a qual Hijjar (2003) vê como um dos quatro "P"'s do Marketing. Neste caso, é o P de praça. 0 sistema logístico é responsável por garantir que os níveis de serviço determinados pela empresa, sejam capazes de fazê-la atingir o posicionamento de mercado esperado. Um bom nível de serviço pode garantir à empresa a geração de receitas adicionais, enquanto o não atendimento de um determinado patamar de serviço pode fazer com que a empresa perca mercado.

\section{RESULTADOS DE UM PROGRAMA DE REDUÇÃO DE CUSTOS EM TRANSPORTES RODOVIÁRIOS EM UMA MULTINACIONAL DISTRIBUIDORA DE COMBUSTÍVEIS LÍQUIDOS.}

O estudo de caso refere-se a multinacional distribuidora de combustíveis líquidos que desde 
2001 vem passando por um processo de transformação para que seus resultados estejam em linha com a visão global da empresa, de "Ser a companhia global de energia mais admirada por seu pessoal, suas parcerias e seu desempenho".

Após um processo de fusão global em 2001, a empresa estudada lançou um programa para otimizar as diversas áreas da empresa, de modo a reduzir custos e tornar-se uma empresa global competitiva, gerando grande retorno aos acionistas e reduzindo principalmente $o$ número de acidentes de trabalho, que geravam altas despesas à empresa.

Para alcançar a altos níveis de excelência, eram necessárias intervenções em diversas áreas de negócio da companhia, e para isso foi criado o programa GDTOP - Global Downstream Optimization Process. Este programa, consistiu em um conjunto de processos que iriam ser otimizados, através de revisão e de implementação de novas práticas que visassem alcançar a excelência operacional.

Por seu um transporte de risco, a indústria do petróleo tem como a logística de distribuição de refinados uma atenção toda especial. Acidentes envolvendo caminhões-tanque, geralmente trazem grandes prejuízos tanto financeiramente, quanto ambientalmente, além de manchar a imagem da empresa.

Pesadas multas e indenizações já foram pagas após acidentes envolvendo transporte de combustíveis e não raro um pode ser visto nas estradas do país.

Por isso, o foco em segurança das distribuidoras de combustíveis é bem grande (principalmente as multinacionais), e o índice de incidentes tem influência direta no preço das ações internacionais destas empresas.

Na América Latina, este programa iniciou-se em 2001 e na área de logística vários resultados foram alcançados em pouco tempo, como será mostrado a seguir.

Em 2001, a situação da frota da empresa era bastante precária. Os caminhões possuíam idade média de 16 anos (considerando conjunto cavalo-carreta), ou seja, a maioria dos equipamentos foi fabricado em 1985. Essa é considerada uma idade muito alta, visto o desgaste que este tipo de caminhão sofre, mesmo tendo os tanques feitos de aço carbono.

A empresa possuía nada mais, nada menos do que 92 transportadores contratados para a realização dos serviços de entrega aos clientes, operando em 55 terminais de distribuição no país. Alguns terminais possuíam até 3 transportadores fazendo o serviço, sendo que cada um era responsável por uma região diferente.

Além disso, a capacidade média dos caminhões em 2001 era de apenas $15 \mathrm{~m} 3$, ou seja, havia uma desconcentração do volume, o que mostra ineficiência. Pedidos de qualquer tamanho eram colocados pelos clientes e faziam com que a distribuidora tivesse que possuir os mais variados caminhões para atender a demanda. Nem sempre, a demanda era atendida prontamente, o que gerava insatisfação aos clientes e excessivo número de reclamações ou retornos de produtos.

Por fim, a frota da Empresa estudada era composta de 1200 caminhões-tanque em todo o país. Um número considerado elevadíssimo e de difícil controle, pois com essa quantidade de caminhões trafegando nas ruas e estradas o risco de acidentes era consequentemente muito maior do que uma frota reduzida. 
Além disso, como um elevado número de transportadoras era difícil padronizar processos ou exigir padrões elevados para a contratação de motoristas, mais um agravante. Assim, a frota além de grande e ineficiente era perigosa, pois não-raro eram encontrados casos de motoristas com habilitações vencidas, ou pior, dirigindo embriagados pelas estradas.

Em 2001, foi iniciado o GDTOP - Fase 1, que estava previsto ir até o final de 2003.

Os grandes objetivos desta fase eram:

- Criar uma política de entregas

- Concentrar volumes

- Eliminar os transportadores com mau desempenho em segurança

Já em 2001, foi criada a política de entregas onde:

A primeira medida apontada foi o de criação de uma política de entregas, que consistia no seguinte:

Para o cliente seus pedidos atendidos, ele deveria fazê-los e tê-los aprovados até 15 horas do dia anterior a data de entrega desejada. Dentro dessa condição:

- Pedidos de $30 \mathrm{~m}^{3}$ ou maior de $30 \mathrm{~m}^{3}$ deveriam ser faturados e embarcados com prazo de 24 horas a partir da data de entrega desejada pelo cliente.

- Pedidos menores que $30 \mathrm{~m}^{3}$ e maiores que $5 \mathrm{~m}^{3}$, deveriam ser embarcados e faturados até 48 horas depois da data de entrega desejada pelo cliente;

- Pedidos de $5 \mathrm{~m}^{3}$ ou menores que isso não tinham prazos determinados para entrega, porém seu prazo máximo seria de 1 semana, visto que no sistema da empresa, o pedido após esse prazo "caduca" e á automaticamente cancelado

Essa política foi o centro do programa GDTOP, onde a concentração de volume pode ser vista, principalmente na queda dos pedidos de $5 \mathrm{~m}^{3}$, e o aumento dos pedidos de $30 \mathrm{~m}^{3}$.

Em relação ao número de transportadores, em 2001 eram 92 contratados, com uma frota com idade média de 16 anos. Já em 2002, a empresa reduziu esse número para 32 transportadores contratados, e 550 caminhões, ou seja, de 54\% no número de caminhõestanque, reduzindo riscos de incidentes e principalmente custos.

Ao se concentrar volume, faz-se com que as viagens dos caminhões tenham menos entregas, ou seja, menos pontos de parada. Ao se reduzir caminhão, desafoga-se os terminais de carregamento, reduzindo assim custos fixos. Os caminhões-tanque puderam fazer mais viagens por dia, mais rápidas e isso fez com que os transportadores com melhor estrutura tivessem ganhos com frente em escala maior.

A redução não parou por ai, em 2002 a redução continuou e o número de transportadores passou para 32, chegando a 17 em 2003.

O número de caminhões-tanque passou a acompanhar este ritmo: 1200 em 2001, 550 em 2002 e 520 em 2003. 
Na fase II do GDTOP que foi de 2003 até os dias atuais, os objetivos eram:

- criar parcerias concretas com o número ideal de transportadores no Cone Sul

- aumentar o número dos chamados full loads (uma entrega por viagem)

- normalizar a demanda (evitando picos em determinados dias da semana e subutilização em outros),

- reduzir mais ainda o número de incidentes (buscando sempre nenhum incidente)

- aumentar o número de viagens por dia dos caminhões-tanque

- estender a janela de horário de recebimento de produto por parte dos clientes

No final de 2004 e início de 2005, ocorreu o chamado RFP - Request For Proposal, onde a Empresa estudada fez uma concorrência entre os 20 melhores transportadores do mercado, para que fossem escolhidos aqueles que oferecessem melhor preço de frete e melhor serviço.

Nesta etapa, os transportadores participantes preencheram uma planilha extensa, que pediam informações sobre seu negócio, seu posicionamento no mercado, seus registros de incidentes, prêmios e de trabalho com outras distribuidoras. É uma prática bastante saudável no mercado, segundo Nazário e Abrahão (2003), onde a troca de informações faz com que o processo de seleção seja estruturado e a avaliação mais clara e justa.

Após a verificação dos resultados, 11 transportadores foram escolhidos, para autuarem junto a empresa estudada. Isso trouxe uma economia de US\$1,66 milhões de dólares.

Em trabalho conjunto com a área de Vendas, os full loads (uma entrega por viagem) foram aumentados. 0 índice de full loads que era no início de 2005 de 35\% subiu para 69\% no final de 2006.

A normalização da demanda era outro item, que onde a área de vendas teve participação importante. Em alguns dias da semana, o volume para entrega era muito alto, principalmente nas quintas-feiras e sextas, pois o prazo médio de pagamento era de dois dias.

Assim, ao pedir na quinta ou na sexta, os clientes ganhavam mais um dia (sábado e domingo os bancos não funcionam) e podiam pagar com mais tranqüilidade na Segunda-Feira.

Assim, havia um pico nestes dias e uma subutilização em dias como terça e quarta.

Isso não gerava uma otimização da frota durante a semana. Com um trabalho feito, junto a área de Vendas e os clientes, os resultados em normalização de Demanda foram de 68\% no ínicio de 2005 para 85\% em meados de 2006, e neste patamar está até os dias atuais.

Todas estas medidas, como já comentando anteriormente, fez com que o número de viagens por dia dos caminhões-tanque fosse aumentado. Em 2001, esse número era de 0,5 viagens por dia, ou seja, a frota ficava ociosa, e muitos caminhões não eram utilizados. Já no final de 2005, o índice era de 1,86 viagens por dia, ou seja, na média do Cone Sul, os caminhões davam quase duas viagens por dia.

A redução no número de acidentes também foi bastante significativa. Em 2005, foram registrados apenas 3 acidentes leves, sem fatalidades e sem pessoas afastadas do trabalho. Em 2006, o número se manteve, também sem acidentes graves. Isso representa uma economia 
que não é vista, quando analisada sozinha, mas quando se compara com o gasto em outros anos como 2001, vê-se que a redução é bastante significativa.

\section{CONCLUSÃo}

Após a demonstração dos conceitos básicos que norteiam este trabalho e da análise detalhada das práticas e resultados obtidos em processo de redução de custos em transportes rodoviários, na empresa distribuidora de petróleo estudada, pode-se retirar algumas conclusões.

Num mercado competitivo, onde as empresas buscam um posicionamento estratégico baseado em liderança de custos, a área de Logística tem uma importância fundamental no alcance de reduções significativas, visto que sua operacionalização por si só gera grandes despesas.

Um trabalho demonstrado, como o GDTOP em Logística na Empresa estudada pode ter um impacto significativo para toda uma organização, pois a economia gerada, acaba liberando recursos que a empresa poder aplicar em outras áreas e ampliar sua atuação no mercado, ou mesmo utilizar os recursos em aplicações financeiras ou outros programas de marketing.

A otimização de frota é um pilar fundamental de uma redução de custos em transportes rodoviários, pois é através dela onde os custos fixos são diluídos e o aproveitamento dos equipamentos é ampliado. Assim, otimizar a frota por si só já gera uma redução significativa de custos.

Por fim, espera-se que com o trabalho apresentado, novas empresas possam encontrar uma fonte para iniciar um programa de redução de custos em transportes rodoviários, estudantes possam ter mais informações sobre o assunto e estudiosos possam usá-lo como exemplos para montagem de outros trabalhos.

\section{REFERÊNCIAS BIBLIOGRAFICAS}

BALLOU, Ronald H. Logística Empresarial. 1 ed. São Paulo: Atlas, 1980.

BERTAGLIA, Paulo Roberto. Logística e Gerenciamento da Cadeia de Abastecimento . 4 ed. São Paulo: Saraiva, 2006.

BOWERSOX, Donald; GLOSS, David. Logística Empresarial - O Processo de Integração da Cadeia de Suprimento. 1 Ed. Atlas: São Paulo, 2001.

DIAS, Marco Aurélio P. Administração de Materiais - Uma abordagem Logística. 4 ed. São Paulo: Atlas, 1993.

FIGUEIREDO, Kleber Fossati; FLEURY, Paulo Fernando; WANKE, Peter. Logística e Gerenciamento da Cadeia de Suprimentos. 1 ed. São Paulo: Atlas, 2003.

FIGUEIREDO, Kleber Fossati; FLEURY, Paulo Fernando; WANKE, Peter. Logística Empresarial.1 ed. São Paulo: Atlas, 2006.

GARDNER, Jonh T: COOPER, Martha C. Understanding shipper-carrier and shipperwarehouser relationships: partnerships revisited. Journal of Business Logistics v.15, n2, p121-143, 1994.

HIJJAR, Maria Fernanda. Serviço ao cliente no sistema logístico. Logística e Gerenciamento 
Redução de custos em transportes rodoviários: o estudo de caso de uma distribuidora multinacional de combustíveis líquidos

da Cadeia de Suprimentos. 1 ed.p143-153 São Paulo: Atlas, 2003.

KANTER, Rosabeth Moss. Collaborative advantage. Harvard Business Review, July-Aug. p.96108, 1994.

LIMA, Mauricio Pimenta: Custeio do transporte rodoviário de Cargas. 1 ed. São Paulo: Atlas, 2003.

LA LONDE, Berbard J. COOPER, Martha C. Parternships in providing customer service: a third party perspective. Illinois: Council of Logistics Management, 1989.

NAZÁRIO, Paulo; ABRAHAO, Fábio. RFI Como ferramenta de planejamento e controle.

São Paulo: Atlas, 2003.

PORTER, Michael. Vantagem Competitiva - Criando e sustentando um desempenho superior. 2 ed. Campus: São Paulo, 1989.

SLACK, N.; CHAMBERS, S. Administração da Produção. 2 ed.São Paulo: Atlas,1997. 